Iranian Quarterly Journal of Breast Disease 2018; 11(3):7.

\title{
Effect of Compassion-Focused Therapy on Body Image and Marital Satisfaction in Women with Breast Cancer
}

\author{
Khalatbari J: Department of psychology, Tonekabon Branch, Islamic Azad University, Mazandaran, Iran \\ Hemmati Sabet V: PhD Student in Psychology, Islamic Azad University of Kermanshah Branch, Kermanshah, \\ Iran \\ Mohammadi H: PhD Student in health Psychology, Tonekabon Branch, Department of Psychology, \\ Mazandaran, Iran
}

Corresponding Author: Javad Khalatbari, Javadkhalatbaripsy2@gmail.com

\begin{abstract}
Introduction: Breast cancer is one of the most common cancers among women. The purpose of this study was to investigate the effectiveness of compassion focused therapy on body image and marital satisfaction in women with breast cancer.

Methods :This research utilized a pre-test and post-test semi-experimental design with a control group. A total of 30 subjects were selected from women with breast cancer presenting to Imam Khomeini Hospital in Tehran in 2017. They were then randomly assigned to experimental and control groups $(\mathrm{n}=15$ for each group). The experimental group received a compassion focused therapy for eight sessions of 90 minutes, but the control group did not receive any intervention. The research instruments were body image questionnaire of Cash (2000) and Enrich marital inventory of Fowlers and Olson (1989). Data were analyzed by multivariate analysis of covariance
\end{abstract}

Results: The mean post-test scores of the experimental group in the components of the body image were apparent evaluation $(\mathrm{P}<0.043)$, apparent tendency $(\mathrm{P}<0.006)$, fit assessment $(\mathrm{P}<0.001)$, tendency to fit $(\mathrm{P}<0.001)$, appearance assessment $(\mathrm{P}<0 / 030)$, health tendency $(\mathrm{P}<0.001)$, tendency to disease $(\mathrm{P}<0.001)$, satisfaction of body parts $(\mathrm{P}<0.001)$, mental retardation with overweight $(\mathrm{P}<0.001))$, Selfclassification of weight $(\mathrm{P}<0.003)$ is less than the mean post-test scores of the control group $(\mathrm{P}<0.05)$. Also, the experimental and control groups have a significant difference in terms of marital satisfaction components $(\mathrm{P}<0.05)$, personality issues $(\mathrm{P}<0.001)$, marital relationship $(\mathrm{P}<0.007)$, solving in contractual response components $(\mathrm{P}<0.02)$, satisfaction $(\mathrm{P}<0.001)$, financial management $(\mathrm{P}<0.001)$, time and leisure $(\mathrm{P}<0.002)$, sexual relations $(\mathrm{P}<0 / 01)$, parenting $(\mathrm{P}<0.001)$, relatives and relatives $(\mathrm{P}<0.001))$, Male and female equality $(\mathrm{P}<0.014)$, ideological orientation $(\mathrm{P}<0.007)$, the experimental group was significantly more than marital satisfaction in the control group $(\mathrm{P}=0.001)$.

Conclusion: The results of this study showed that compassion focused therapy can affect the body image and marital satisfaction in women with breast cancer.

Keyword: Compassion Focused Therapy, Body Image, Marital Satisfaction, Breast Cancer 